\title{
Exploring the Socio-Emotional Factors Associated with Subjective Well-Being in the Unemployed
}

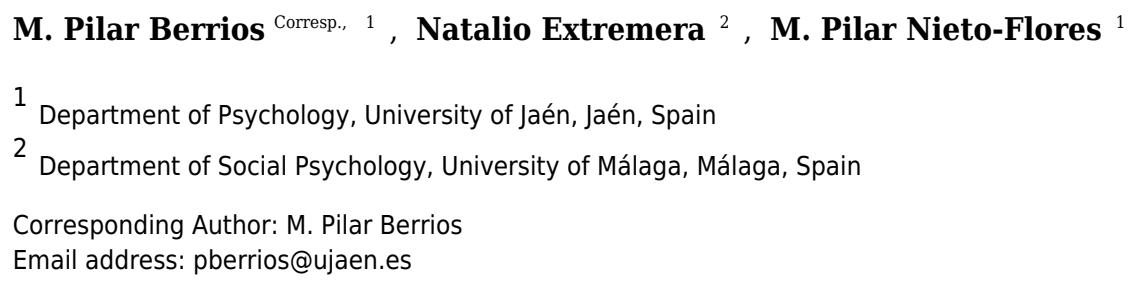

In this study, we examined the relations between dimensions of Perceived Emotional Intelligence (PEI) and classic constructs, such as social support, on depression, stress, and subjective well-being indicators (life satisfaction and happiness). The study also sought to determine whether PEI dimensions accounted for a significant portion of the variance beyond that of classic constructs in the study of depression, stress, and well-being outcomes in a sample of 442 unemployed subjects. Results indicated that social support and all PEI dimensions are found to be significant and negatively related to depression and stress, and these variables were also found to be significant and positively associated with life satisfaction and happiness. Additionally, results using regression analysis indicated that PEI, and specifically use of emotions and regulation of emotions, explain a significant amount of the variance of all outcomes after controlling for socio-demographics and social support dimensions. Finally, theoretical and practical implications of these constructs and their relation with psychological adjustment and well-being in unemployed people are discussed. 
1 Running Head: SOCIO-EMOTIONAL FACTORS IN THE UNEMPLOYED

3 Exploring the Socio-Emotional Factors Associated with Subjective Well-Being in the

4 Unemployed

5

$6 \quad$ M $^{\mathrm{a}}$ Pilar Berrios ${ }^{1}$, Natalio Extremera ${ }^{2}, \mathrm{M}^{\mathrm{a}}$ Pilar Nieto-Flores ${ }^{3}$

$8{ }^{1}$ Department of Psychology, University of Jaen, Spain.

$9 \quad 2$ Department of Social Psychology, University of Malaga, Spain.

$10{ }^{3}$ Department of Psychology, University of Jaen, Spain.

11

12 Corresponding Authors: Ma Pilar Berrios, PhD, Department of Psychology, University of Jaen,

13 Spain, Campus Las Lagunillas Edificio Humanidades y Ciencias de la Educación (C5),

14 Dependencia: C5-156, Jaén, Spain.

15 pberrios@ujaen.es, Phone: (+34) 953 212291, Fax: (+34) 953211881 


\section{Exploring the Socio-Emotional Factors Associated with Subjective Well-Being in the}

\section{Unemployed}

\section{INTRODUCTION}

Unemployment remains a major economic and social problem in the European Union. According to the Eurostat database, the unemployment problem has been most acute in Greece, Spain, Portugal, and Italy (Eurostat, 2016). In 2016, Spain has the second highest European Union unemployment rate, after Greece. In short, the national unemployment rate in the first quarter of 2016 for Spain was 21\% with 4,791,400 individuals unemployed (INE, 2016). Therefore, unemployment is one of the biggest problems for European countries, not only because of its socio-economic impact, but also because of its psychological consequences. The psychosocial impact of job loss is considered to be a major stressful event with long-term consequences for individuals (Wanberg, 2012). Accordingly, it is well documented that job loss is associated with a significant increase in psychological distress, depression, and worsening mental health (Paul \& Moser, 2009; Stankunas et al., 2006), and it is associated with a significant decrease in psychological well-being (McKee-Ryan et al., 2005). Therefore, analysis of personal resources that help to improve the experience of unemployment remains an issue of great interest to researchers and career counsellors (Rey, Extremera \& Peláez-Fernández, 2015). One of the main avenues of research has focused on the role of cognitive-affective variables, which would facilitate coping with these demands and would increase the levels of well-being (McKee-Ryan et al., 2005). Numerous psychosocial predictors of mental health and well-being in unemployment have been examined to better understand this relationship. These resources will ameliorate the potentially negative consequences of unemployment and consequently provide 
protection. Social support and Emotional Intelligence (EI) might be considered two of these psychosocial resources.

\section{Social support, psychological adjustment and well-being}

Social support can be defined as the perception or experience that one is loved and cared for, esteemed, and valued, and part of a social network of communication and mutual assistance (Wills, 1991). A consistent body of research has emerged over recent decades to show that close relations with family, friends, and significant others is a protective factor that helps guard against the deleterious mental and health effects of unemployment (Bjarnason \& Sigurdardottir, 2003). Thus, lack of social support is positively related to depressive and anxious symptomatology, both in the general population (Siedlecki et al., 2014) and among the unemployed population (Rey, Extremera \& Peláez-Fernández, 2015). Similarly, social support has been found to have a particularly marked effect on how well individuals cope with unemployment, that is, unemployed people cope with the loss of a job more successfully if they have a wide social support network (Bjarnason \& Sigurdardottir, 2003; Seblarska, Morse \& Gunnesch-Luca, 2009) In sum, the adverse impact of unemployment on the psychological adjustment and wellbeing of unemployed individuals in supportive social contexts might be less than its effect on unemployed individuals living in less supportive contexts (Rey, Extremera \& Peláez-Fernández, 2015).

\section{Emotional intelligence, psychological adjustment and well-being}

There are currently two predominant models of EI: mixed and ability models (Mayer, Roberts \& Barsade, 2008). Mixed models describe EI as a broad conception of intelligence that combines social skills, traits, and dispositional behavior. On the other hand, Mayer and Salovey's (1997) ability model of EI involves the ability to carry out accurate reasoning about 
emotions and the ability to use emotions and emotional knowledge to enhance thought, thus enabling the subject to solve social problems and to adapt effectively to the environment (Mayer, Roberts \& Barsade, 2008). In the operational definition of EI, these authors distinguish four specific skills: (1) ability to identify and express emotions, (2) ability to use emotions in decision-making, (3) ability to understand emotions, and (4) ability to regulate emotions, both in oneself and in others.

A recent line of research has focused on the unique contributions of EI in explaining the psychological adjustment and well-being of different collectives controlling for classic constructs (Zeidner, Matthews \& Roberts, 2012). The results of this research indicate that EI is negatively related to stress and depression (Augusto et al., 2008; Salguero, Extremera \& FernándezBerrocal, 2012), and positively related to various indicators of well-being (Gallagher \& VellaBrodrick, 2008; Por et al., 2011). All these findings were obtained in samples of the general population, but data on these relationships for unemployed people remain scarce. Prior studies have found that self-regulatory processes may exert influence on both longer-term affective states and on the mental health of individuals who lose their jobs (Wanberg et al., 2012). These results suggest that affective and personal resources are important to subjective well-being and psychological adjustment during unemployment (McKee-Ryan et al., 2005).

In sum, social support and EI might be resources that can help individuals to better cope with stressful situations, such as unemployment, and to increase psychological adjustment and well-being.

\section{Motivation for the present study}

Previous literature has confirmed empirical evidence of the relationship between social support and psychological adjustment and subjective well-being in unemployed people. Despite 
85 these findings, researchers have not examined the joint contribution of social support and EI dimensions to well-being and psychological adjustment during unemployment. These findings might be significantly useful in the design and development of employment promotion programs and clinical interventions with unemployed people.

Given the aforementioned considerations, the purpose of this study was twofold. The first purpose was to examine the relationships between social support, EI dimensions, stress, depression, and indicators of subjective well-being (life satisfaction and happiness) in a sample of unemployed people. Second, we examined the incremental validity of EI dimensions on stress, depression, and well-being outcomes beyond what is accounted for by the influence of social support. According to the aforementioned studies, higher levels of social support and EI dimensions are expected to be negatively associated with psychological distress and depression and positively associated with well-being outcomes. Thus, our study hypothesized that EI dimensions will explain further additional variance in psychological distress, depression, and well-being outcomes after removing any variance explained by social support.

\section{MATERIALS AND METHODS}

\section{Participants}

The sample was composed of 442 unemployed people (225 males and 217 females) from two southern cities in Spain, who participated voluntarily and anonymously in the study. The mean age was 32.2 years $(\mathrm{SD}=9.9)$. The average duration of unemployment was 20.28 months ( $\mathrm{SD}=30.7$ months). The marital status of the participants was: $59.8 \%$ single, $13.5 \%$ married, $1.5 \%$ divorced, $16.2 \%$ widow(er), and $9 \%$ cohabiting.

\section{Instruments}

\section{Social Support}


The Multidimensional Scale of Perceived Social Support (MSPSS) (Zimet et al., 1988) consists of twelve items relating to perceived social support and is answered on a seven-point Likert-type scale, ranging from 1 (strongly disagree) to 7 (strongly agree). Three separate scores can be calculated for the sources of support: (1) Significant Other, (2) Family, and (3) Friends, which can be added together to give a total social support score. Higher scores indicate greater perceived social support. We used the validated Spanish version (Landeta \& Calvete, 2002).

\section{Emotional Intelligence}

The Wong and Law Emotional Intelligence Scale (WLEIS) (Wong \& Law, 2002) was used to measure EI abilities. This self-report measure is based on the definition of EI proposed by Salovey and Mayer (1990) and consists of four dimensions: (1) self-emotion appraisal, (2) other-emotion appraisal, (3) use of emotion, and (4) regulation of emotion. Each subscale consists of four items with a seven-point response format, ranging from 1 (strongly disagree) to 7 (strongly agree). The scale includes items such as: "I am quite capable of controlling my own emotions". This version of WLEIS has been shown to have good validity and reliability in Spanish populations (Pena, Rey \& Extremera, 2012; Rey \& Extremera, 2011).

\section{Depression, Anxiety and Stress}

The Depression Anxiety Stress Scale-21 (DASS-21) (Lovibond \& Lovibond, 1995), which aims to measure psychological distress was developed according to the tripartite model of anxiety and depression and is a set of three self-report scales designed to measure the negative emotional states of depression, anxiety, and stress. Each of the three DASS scales contains seven Likert-type scales. Alpha coefficients are all above .85 and validity has been supported through its correlation with other measures of depression and anxiety (Lovibond \& Lovibond, 1995). The Spanish version showed satisfactory internal consistency, convergent validity, 
131 and an acceptable divergent validity (Bados, Solanas \& Andrés, 2005). In our study, we used

132 stress and depression subscales.

\section{Life satisfaction}

We used the Spanish version (Atienza, Balaguer \& Garcia-Merita, 2003) of the

Satisfaction With Life Scale (SWLS) (Diener et al., 1985) to assess perceived global life satisfaction. This scale comprises five self-referencing statements and requires subjects to rate the extent to which they agree or disagree with each statement on a seven-point scale $(1=$ strongly disagree to $7=$ strongly agree). Both English and Spanish versions have shown evidence for discriminant validity and appropriate internal consistency (Atianza, Balaguer \& GarciaMerita, 2003; Diener et al., 1985).

\section{Happiness}

The Subjective Happiness Scale (SHS) (Lyubomirsky \& Lepper, 1999) is a widely used, 4-item global assessment of happiness. Two items request respondents to describe themselves using both absolute ratings and ratings relative to peers, whilst the other two items offer brief descriptions of happy and unhappy individuals and ask respondents about the extent to which each description describes them. Each item was assessed on a seven-point Likert scale (e.g., "In general I consider myself": 1 = Not a very happy person to 7 = A very happy person). Across 14 samples, the SHS has demonstrated good psychometric properties, such as test-retest reliability, discriminant validity, and convergent validity (Lyubomirsky \& Lepper, 1999). Furthermore, the Spanish SHS has recently been translated into Spanish with satisfactory psychometric qualities. We used a well-validated Spanish version (Extremera \& Fernández-Berrocal, 2014).

\section{Procedure}

Participants who were utilizing the national employment office in a province of southern 
154 Spain completed a survey about social resources, emotions, psychological adjustment, and well-

155 being. The survey also included measures of social support, Perceived Emotional Intelligence

156 (PEI), stress symptomatology, depressive symptomatology, life satisfaction, and happiness,

157 along with questions related to socio-demographics variables such as age, gender, and period of

158 unemployment. The order in which participants answered the measuring instruments was as

159 follows: first they responded to questions related to socio-demographics variables, this was

160 followed by the scales of social support, PEI, depressive symptomatology and stress

161 symptomatology, life satisfaction, and, finally, they completed the scale that measures the global

162 level of happiness. Data were collected over four consecutive months with the help of a team of

163 research assistants. All subjects were informed that they would be asked to participate in a

164 research study concerned with personality and emotions, and informed consent was obtained.

165 Respondents received no financial compensation for participation in the study.

166 The study was carried out in accordance with the Declaration of Helsinki and the ethical

167 guidelines of the American Psychological Association. The study protocol was approved by the

168 Research Ethics Committee of the University of Jaén.

169

170

171

172

173

174

175

176

\section{Statistical analysis}

Preliminary analyses were carried out to compute descriptive statistics and internal consistency, as well as to detect correlations among social support, PEI dimensions, depressive symptomatology, stress symptomatology, and subjective well-being indicators (life satisfaction and happiness). To check whether PEI dimensions are related to depressive symptomatology, stress symptomatology, and subjective well-being indicators (even after controlling for the influence of social support), we conducted a three-step hierarchical regression in which sociodemographic variables were entered first (as control variables), followed by social support, and, 
177 finally, PEI dimensions (self-emotion appraisal, other-emotion appraisal, use of emotion, and 178 regulation of emotion).

These analyses were carried out using the SPSS package (version 20.0; IBM, Chicago,

180

IL).

\section{RESULTS}

182

183

184

185

186

187

188 189

1. Social support

2. Self-emotion appraisal

3. Other-emotion appraisal

4. Use of emotions

5. Regulation of emotions

6. Depression

7. Stress

8. Life Satisfaction

9. Happiness

$\mathrm{M}$

SD

$\alpha$

190

Note: ${ }^{* *} p \leq .01,{ }^{*} p \leq .05$

$\begin{array}{lllllllll}1 & 2 & 3 & 4 & 5 & 6 & 7 & 8 & 9\end{array}$

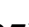

$.27^{* *}$

$26^{* *}$

$.61^{* *}-$

$.26^{* *} \quad .64^{* *} \quad .51^{* *} \quad-$

$\begin{array}{llll}.20^{* *} & .61^{* *} & .41^{* *} & .59^{* *}\end{array} \quad-$

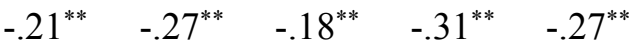

$\begin{array}{llllll}-.10^{*} & -.22^{* *} & -.13^{* *} & -.19^{* *} & -.30^{* *} & .84^{* *}\end{array}$

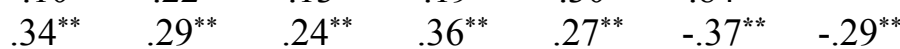

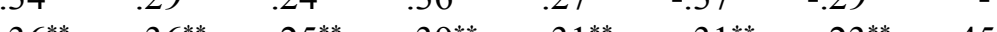

\begin{tabular}{lllllcccc}
$.36^{* *}$ & $.36^{* *}$ & $.25^{* *}$ & $.39^{* *}$ & $.31^{* *}$ & $-.31^{* *}$ & $-.23^{* *}$ & $.45^{* *}$ & - \\
\hline 5.72 & 5.36 & 5.36 & 5.28 & 4.95 & 1.08 & 1.42 & 4.35 & 4.96
\end{tabular}

$\begin{array}{lllllllll}1.08 & 1.03 & .98 & 1.09 & 1.20 & .89 & .88 & 1.22 & 1.00\end{array}$

$\begin{array}{lllllllll}.91 & .77 & .77 & .80 & .83 & .92 & .90 & .81 & .70\end{array}$

191 


\section{Hierarchical regression analyses}

To examine and evaluate the separate contribution of socio-demographic variables, social support, self-emotion appraisal, other-emotion appraisal, use of emotion, and regulation of emotion for the prediction of depressive symptomatology, stress symptomatology, life satisfaction, and happiness, our study conducted a set of hierarchical regression analyses. For the first step, gender, age, and duration of unemployed were entered as control variables. Second, we entered social support: the well-known and classic dimension that is traditionally associated with psychological adjustment and the psychological well-being of the unemployed,. Finally, PEI dimensions were entered into the regression. To examine whether predictors accounted for a small, medium, or large amount of the variance in psychological adjustment and well-being indicators, we used Cohen's (1988) convention for small $\left(f^{2}=.02\right)$, medium $\left(f^{2}=.15\right)$, and large $(f$ $2=.35$ ) effects. The results of these analyses are presented in Tables 2 and 3 .

As Table 2 shows, a total of $20 \%$ of the variance was accounted for with respect to depressive symptomatology $\left(\mathrm{R}^{2}=.20 ; \mathrm{F}(7,442)=12.63, \mathrm{p}<.001\right)$. In the first step, sex $(\beta=-$ $.04, p>.05)$ did not predict the depression level. However, age $(\beta=.23, p<.001)$ and time of unemployment $(\beta=.10, \mathrm{p}<.05)$ reached statistical significance in predicting the depression scores. In the next step, the classic dimension associated with depressive symptomatology (social support) did not predict the depression level $(\beta=-.06, p>.05)$. In the final step, use of emotions and regulation of emotions had a regression coefficient that reached statistical significance: $(\beta=$ $-.25, \mathrm{p}<.01)$ and $(\beta=-.14, \mathrm{p}<.05)$ respectively, explaining a small but significant amount of variance $\left(\mathrm{f}^{2}=.123\right)$ in the prediction of depression $\left(\Delta \mathrm{R}^{2}=.11\right)$.

A total of $15 \%$ of the variance was accounted for with respect to stress symptomatology $\left(\mathrm{R}^{2}=.15 ; \mathrm{F}(7,442)=9.13, \mathrm{p}<.001\right)$. In the first step, sex $(\beta=.00, \mathrm{p}>.05)$ did not predict the 
215 stress level. However, age $(\beta=.21, \mathrm{p}<.001)$ and period of unemployment $(\beta=.10, \mathrm{p}<.05)$

216 reached statistical significance for predicting the stress scores. In the next step, the classic

217 dimension associated with stress symptomatology — social support — did not predict the stress

218 level $(\beta=.12, p>.05)$. In the final step, regulation of emotions was the only factor that had a

219

220

221

222

223

224

225

226

227

228

229

230

231

232

233

234

235

236

237

238

regression coefficient that reached statistical significance $(\beta=-.31, p<.001)$, explaining a small

but significant amount of variance $\left(\mathrm{f}^{2}=.111\right)$ in the prediction of stress $\left(\Delta \mathrm{R}^{2}=.10\right)$ [See Table 2].

As Table 3 shows, in terms of life satisfaction, a total of $20 \%$ of the variance of life

satisfaction was accounted for $\left(\mathrm{R}^{2}=.20 ; \mathrm{F}(7,442)=12.97, \mathrm{p}<.001\right)$. In step one, $\operatorname{sex}(\beta=-.116$,

$\mathrm{p}>.05)$ and period of unemployment $(\beta=.042, \mathrm{p}>.05)$ did not predict life satisfaction. Age was

the only socio-demographic variable that had a regression coefficient that reached statistical

significance $(\beta=-.09, p<.05)$. In the next steps, social support was associated with life

satisfaction for the unemployed $(\beta=.22, \mathrm{p}<.001)$. In the final step, the use of emotions was the

unique predictor that had a regression coefficient that reached statistical significance $(\beta=.26, p<$

$.001)$, explaining a small but significant amount of variance $\left(\mathrm{f}^{2}=.086\right)$ in the prediction of life

satisfaction $\left(\Delta \mathrm{R}^{2}=.08\right)$.

Finally, with regard to subjective happiness, a total of $25 \%$ of the variance was accounted for $\left(\mathrm{R}^{2}=.25 ; \mathrm{F}(7,442)=17.17, \mathrm{p}<.001\right)$. In step one, the socio-demographic variables did not predict happiness: age $(\beta=-.07, \mathrm{p}>.05)$, sex $(\beta=.07, \mathrm{p}>.05)$, and period of unemployment $(\beta=$ $.07, \mathrm{p}>.05)$. In the second step, social support was associated with the happiness of the unemployed $(\beta=.24, \mathrm{p}<.001)$. In the final step, self-emotion appraisal and use of emotions had a regression coefficient that reached statistical significance: $(\beta=.13, p<.05)$ and $(\beta=.22, p<$ $.001)$ respectively, explaining a small but significant amount of variance $\left(f^{2}=.123\right)$ in the prediction of happiness $\left(\Delta \mathrm{R}^{2}=.11\right)$ [See Table 3]. 
239 Table 2: Results of hierarchical regression analyses of EI dimensions on depression and stress, controlling for sex, 240 age, duration of unemployment, and social support

241

\begin{tabular}{|c|c|c|c|c|c|c|c|c|}
\hline Predictors & & & ressi & & & & ess & \\
\hline & $\beta$ & $\mathrm{R}^{2}$ & $\Delta \mathrm{R}^{2}$ & $\mathrm{~F}$ & $\beta$ & $\mathrm{R}^{2}$ & $\Delta \mathrm{R}^{2}$ & $\mathrm{~F}$ \\
\hline Step 1: demographic variables & & .06 & - & $10.11^{* * *}$ & & .04 & - & $6.48^{* * *}$ \\
\hline Age & $.23^{* * *}$ & & & & $.21^{* * *}$ & & & \\
\hline Sex & -.04 & & & & .00 & & & \\
\hline Time unemployed & $.10^{*}$ & & & & $.10^{*}$ & & & \\
\hline Step 2: traditional predictor & & .09 & .03 & 8.55 & & .05 & .01 & 5.57 \\
\hline Social support & -.06 & & & & .12 & & & \\
\hline Step 3: dimension of EI & & .20 & .11 & $12.63^{* * *}$ & & .15 & .10 & $9.13^{* * *}$ \\
\hline Self-emotion appraisal & -.04 & & & & -.19 & & & \\
\hline Other-emotion appraisal & .05 & & & & .35 & & & \\
\hline Use of emotions & $-.25^{* *}$ & & & & -.05 & & & \\
\hline Regulation of emotions & $-.14^{*}$ & & & & $-.31^{* * *}$ & & & \\
\hline
\end{tabular}

242 Note: Betas from the final step of the regression; ${ }^{* * * *} p \leq .001,{ }^{* * *} p \leq .01,{ }^{*} p \leq .05$

243

244 Table 3: Results of hierarchical regression analyses of EI dimensions on psychological well-being indicators, 245 controlling for sex, age, duration of unemployment and social support

246

\begin{tabular}{|c|c|c|c|c|c|c|c|c|}
\hline \multirow[t]{2}{*}{ Predictors } & \multicolumn{4}{|c|}{ Life Satisfaction } & \multicolumn{4}{|c|}{ Happiness } \\
\hline & $\beta$ & $\mathrm{R}^{2}$ & $\Delta \mathrm{R}^{2}$ & $\mathrm{~F}$ & $\beta$ & $\mathrm{R}^{2}$ & $\Delta \mathrm{R}^{2}$ & $\mathrm{~F}$ \\
\hline Step 1: demographic variables & & .01 & - & 2.00 & & .01 & - & 1.59 \\
\hline Age & $-.09^{*}$ & & & & -.07 & & & \\
\hline Sex & .04 & & & & .07 & & & \\
\hline Time unemployment & -.04 & & & & .07 & & & \\
\hline Step 2: traditional predictor & & .11 & .10 & $13.75^{* * *}$ & & .14 & .13 & $16.63^{* * *}$ \\
\hline Social support & $.22^{* * *}$ & & & & $.24^{* * *}$ & & & \\
\hline Step 3: dimension of EI & & .20 & .08 & $12.97^{* * *}$ & & .25 & .11 & $17.17^{* * *}$ \\
\hline Self-emotion appraisal & .03 & & & & $.13^{*}$ & & & \\
\hline Other-emotion appraisal & -.01 & & & & -.06 & & & \\
\hline Use of emotions & $.26^{* * *}$ & & & & $.22^{* * *}$ & & & \\
\hline Regulation of emotions & .06 & & & & .10 & & & \\
\hline
\end{tabular}

247 Note: $\quad$ Betas from the final step of the regression; ${ }^{* * *} p \leq .001,{ }^{* *} p \leq .01,{ }^{*} p \leq .05$ 
248

249

250

251

252

253

254

255

256

\section{DISCUSSION}

Theoretical models of coping with job loss suggest that psychosocial factors may be important predictors of psychological distress and low levels of well-being (McKee-Ryan \& Kinicki, 2002). Examining the personal resources that protect people or place them at greater risk for the adverse health consequences of unemployment remains an important focus for both social researchers and career counselors. The main objective of this study was to determine the unique and additional contribution of emotional intelligence skills on psychological distress, depression, and well-being outcomes during unemployment, in combination with the other traditional predictor of levels of distress and well-being during unemployment (social support).

Previous research has consistently documented the detrimental effect on mental health and well-being that follows job loss (McKee-Ryan \& Kinicki, 2002). In fact, unemployment has traditionally been related to lower levels of well-being and related to higher levels of stress, depression, and anxiety, among others (McKee-Ryan et al., 2005; Wanberg, Kammeyer-Mueller \& Shi, 2001).

Our results have showed that social support was negatively related to depressive symptomatology and stress symptomatology and positively related to life satisfaction and happiness. Furthermore, a similar pattern was found with EI dimensions. Specifically, all EI dimensions were also negatively related to symptoms of depression and stress and positively related to life satisfaction and happiness in the unemployed. These results are in line with previous research and they extend prior work by underlining that these psychosocial resources might weaken the negative psychological consequences of unemployment (depression and stress) (Bjarnason \& Sigurdardottir, 2003; Wanberg et al., 2012). Similarly, these personal resources 
270 might also promote higher levels of well-being in the unemployed (McKee-Ryan et al., 2005;

271 Rey et al., 2015).

Regression analyses indicated that, beyond traditional socio-demographic variables, social support was not a significant predictor of depression and stress levels. However, social support did explain a significant percentage of variance in life satisfaction and happiness. These findings are consistent with the available empirical evidence, according to which social support is one of the main sources of subjective well-being (Siedlecki et al., 2014), and also with past research on the link between social support and higher well-being in unemployed people (Rey et al., 2015).

However, our results have shown that one of the dimensions of PEI, use of emotions, was a significant predictor after controlling for socio-demographic variables and social support, except for stress. This PEI dimension is related to a person's ability to make use of his or her emotions by directing them toward constructive activities and personal performance. An unemployed individual who is highly capable in this ability would be able to encourage him/herself to continuously do better in coping with job loss. Furthermore, those unemployed people that have highly developed abilities to use and reason about emotions would also be able to direct their emotions in positive and productive directions. They might also be better able to control their affective reactions in response to unemployment depression and report higher life satisfaction and happiness compared to their unemployed counterparts with a low ability to use emotions. Thus, after controlling for the demographic variables and other well-known dimensions, such as social support, use of emotional skills explained a significant and additional variance in three out of four well-being outcomes. These results with the unemployed partially replicate the results obtained in previous cross-sectional studies with other samples in which use 
293 of emotions, assessed by WLEIS, was the most important predictor of all PEI dimensions in 294 predicting depression levels (Shi \& Wang, 2007), life satisfaction (Law, Wong \& Song, 2004), 295 and happiness (Khosla \& Dokaina, 2010).

Moreover, after controlling for socio-demographics and social support, the ability to regulate emotions was the only resource that explained significant variance in stress symptomatology. It is tentative to think that unemployed people who are highly capable of regulating their own emotions would be better able to manage stressful situation by carrying out social and cognitive strategies, for example, cognitive reappraisal and emotional acceptance, to effective manage negative emotions (Shallcross, Troy \& Mauss, 2015).

Hence, it is noteworthy that the predictive power of EI abilities appears to be mostly due to the joint contribution of use of emotions and regulation of emotions. Emotional information plays a critical role in our working lives since active job searches are governed by rules of behavior that are triggered by our emotions. Being able to effectively use emotions to facilitate positive thoughts and to regulate emotions and actions may have an impact on health and wellbeing, making unemployed people more adaptable to daily life stressors and more able to use and repair emotions for managing conflicts and difficult situations, such as job rejections, financial adversity, and interviews, among others. Individuals with high use and regulation abilities are thought to clearly discern their moods and to access and generate emotions that assist with optimistic thoughts, motivate positive actions, and mediate negative affects and behaviors, all of which should contribute to greater levels of mental health and well-being. Traditionally, positive psychological approaches have considered that healthy people use psychological and social resources (self-efficacy, optimism, resilience, hope, humor, etc.) to cope with stress, anxiety, and depression, as well as to increase their well-being (Seligman \& 
Csikszentmihalyi, 2000). Our results are in line with this reasoning and extend previous findings that suggest unemployed people who score highly in emotional skills are better equipped to handle stressful situations during unemployment and to report high psychological adjustment and well-being outcomes.

In spite of its contribution to the field, this study is not without certain limitations. First, self-reports were used as a method of assessment of both EI and well-being indicators, which is not the best choice since self-reports are known to be contaminated by inherent shared method variance problems and bias of overestimation (Schutte et al., 2007). Further research with performance measures that test EI and medical health indicators for well-being and distress is needed. Our study included unemployed individuals recruited by purposive sampling methods, which is a non-random sampling technique. A limitation of adopting a purposive sampling is that a small sample size and the non-random nature of the sample may place severe constraints on the ability to generalize findings to the general population. Therefore, these findings need to be replicated with other larger and random unemployed populations in order to generalize our results. Finally, self-emotions appraisal and other-emotions appraisal (two dimensions of the PEI) were not as statistically significant as predictor as were use of emotions and regulation. One possible explanation for these weak associations could be related to the sample size; the use of a greater sample could show more robust associations. A further possibility is that this could be related to the low scores obtained by participants in depression and stress. Therefore, the use of clinical samples with high levels of symptomatology could overcome this limitation.

\section{Conclusions}

To conclude, this research lends credence to those intervention programs that focus in part on stimulating emotional abilities to enhance coping in individuals who experience 
339 challenging and stressful situations during unemployment. Even though our research suggests

340 that specific emotional skills might play an important role in quality of life, further research may

341 better examine specific conditions in which EI is relevant through different stages of

342 unemployment, and may better define what objectives and key results are more important (i.e.,

343 active job searching, employability, psychological adjustment). Including EI training in

344 vocational guidance programs that emphasize the use of emotional skills may have the potential

345 to improve psychological functioning during unemployment (Hodzic et al., 2015). Moreover,

346 further mediational research should examine whether the impact of EI on employability is in part

347 a result of improvement in mental health and well-being. Identifying such factors would also

348 provide valuable information to both career counselors and social researchers in order to design

349 effective assistance interventions to improve quality of life during unemployment.

350

351 ACKNOWLEDGEMENTS

352 We would like to express our heartfelt thanks to all the unemployed people who participated in 353 this study. 


\section{REFERENCES}

Atienza FL, Balaguer I, Garcia-Merita ML. 2003. Satisfaction with Life Scale: analysis of factorial invariance across sexes. Personality and Individual Differences 35:1255-1260 DOI 10.1016/S0191-8869(02)00332-X.

Augusto JM, López-Zafra E, Berrios MP, Aguilar-Luzón MC. 2008. The relationship between emotional intelligence, occupational stress and health in nurses: A questionnaire survey. International Journal of Nursing Studies 45:888-901 DOI 10.1016/j.ijnurstu.2007.03.005.

Bados A, Solanas A, Andrés R. 2005. Psychometric properties of the Spanish version of Depression, Anxiety and Stress Scales. Psicothema 17:679-683.

Bjarnason T, Sigurdardottir TJ. 2003. Psychological distress during unemployment and beyond: Social support and material deprivation among youth in six northern European countries. Social Science \& Medicine 56:973-985 DOI 10.1016/S0277-9536(02)00109-0.

Cohen J. 1988. Statistical power analysis for the behavioral sciences (2nd ed.). Hillsdale, NJ: Erlbaum.

Diener E, Emmons RA, Larsen RJ, Griffin S. 1985. The Satisfaction with Life Scale. Journal of Personality Assessment 49:71-75 DOI 0.1207/s15327752jpa4901_13.

Eurostat unemployment database [cited 2016 26/07/2016]. Available at: $<\underline{\text { http://epp.eurostat.ec.europa.eu }>}$

Extremera N, Fernández-Berrocal P. 2014. The Subjective Happiness Scale: translation and preliminary psychometric evaluation of a Spanish version. Social Indicators Research 119:473-481 DOI 10.1007/s11205-013-0497-2. 
Gallagher EN, Vella-Brodrick DA. 2008. Social support and emotional intelligence as predictors of subjective well-being. Personality and Individual Differences 44:1551-1561 DOI 10.1016/j.paid.2008.01.011.

Hodzic S, Ripoll P, Lira E, Zenasni F. 2015. Can intervention in emotional competences increase employability prospects of unemployed adults? Journal of Vocational Behavior 88:28-37 DOI 10.1016/j.jvb.2015.02.007.

INE. Instituto Nacional de Estadística [National Statistics Institute] [cited 2016 26/07/2016]. Available at: [http://www.ine.es/]

Khosla M, Dokania V. 2010. Does happiness promote emotional intelligence? Journal of the Indian Academy of Applied Psychology 36:45-54.

Landeta O, Calvete E. 2002. Adaptación y validación de la Escala Multidimensional de Apoyo Social Percibido. Ansiedad y estrés 8:173-182.

Law K, Wong C, Song LJ. 2004. The construct and criterion validity of emotional intelligence and its potential utility for management studies. Journal of Applied Psychology 89:483496 DOI 10.1037/0021-9010.89.3.483.

Lovibond P, Lovibond S. 1995. The structure of negative emotional states: Comparison of the depression anxiety stress scales (DASS) with the Beck depression and anxiety inventories. Behaviour Research and Therapy 33:335-343 DOI 10.1016/0005-7967(94)00075-U.

Lyubomirsky S, Lepper HA. 1999. A measure of subjective happiness: Preliminary reliability and construct validation. Social Indicators Research 46:137-155 DOI 10.1023/A:1006824100041.

Mayer JD, Salovey P. 1997. What is emotional intelligence? In: Salovey P, Sluyter D, eds. Emotional development and emotional intelligence: implications for educators. New 
York: Basic Books, 3-31.

Mayer JD, Roberts RD, Barsade SG. 2008. Human abilities: emotional intelligence. Annual Review of Psychology 59:507-536 DOI 10.1146/annurev.psych.59.103006.093646.

McKee-Ryan FM, Kinicki AJ. 2002. Coping with job loss: A life-facet perspective. In: Cooper CL, Robertson IT, eds. International Review of Industrial and Organizational Psychology. Chichester, England: Wiley, 1-29.

McKee-Ryan F, Song Z, Wanberg CR, Kinicki AJ. 2005. Psychological and physical wellbeing during unemployment: a meta-analytic study. Journal of Applied Psychology 90:53-76.

Paul KI, Moser K. 2009. Unemployment impairs mental health: Meta-analyses. Journal of Vocational Behavior 74:264-282 DOI 10.1016/j.jvb.2009.01.001.

Pena M, Rey L, Extremera N. 2012. Bienestar personal y laboral en el profesorado de Infantil y Primaria: Diferencias en función de su inteligencia emocional y del género. Revista de Psicodidáctica 17:341-360 DOI 10.1387/Rev.Psicodidact.1220.

Por J, Barriball L, Fitzpatrick J, Roberts J. 2011. Emotional intelligence: Its relationship to stress, coping, well-being and professional performance in nursing students. Nurse Education Today 31:855-860 DOI 10.1016/j.nedt.2010.12.023.

Rey L, Extremera N. 2011. El apoyo social como un mediador de la inteligencia emocional percibida y la satisfacción vital en una muestra de profesorado. Revista de Psicología Social 26:401-412.

Rey L, Extremera N, Peláez-Fernández MA. 2015. Linking social support to psychological distress in the unemployed: The moderating role of core self-evaluations. Social Indicators Research DOI 10.1007/s11205-015-0958-x. 
422 Salguero JM, Extremera N, Fernández-Berrocal P. 2012. Emotional intelligence and depression: The moderator role of gender. Personality and Individual Differences 53:2932 DOI 10.1016/j.paid.2012.02.006.

Salovey P, Mayer J. 1990. Emotional intelligence. Imagination, Cognition and Personality 9:185-211.

Schutte NS, Malouff JM, Thorsteinsson EB, Bhullar N, Rooke SE. 2007. A meta-analytic investigation of the relationship between emotional intelligence and health. Personality and Individual Differences 42:921-933 DOI 10.1016/j.paid.2006.09.003.

Seligman ME, Csikszentmihalyi M. 2000. Positive psychology: An introduction. American Psychologist 55:5-14 DOI 10.1037/0003-066X.55.1.5.

Shallcross AJ, Troy AS, Mauss IB. 2015. Regulation of Emotions Under Stress. Emerging Trends in the Social and Behavioral Sciences: An Interdisciplinary, Searchable, and Linkable Resource. 1-16 DOI 10.1002/9781118900772.etrds0036.

Shi J, Wang L. 2007.Validation of emotional intelligence scale in Chinese university students. Personality and Individual Differences 43:377-387 DOI 10.1016/j.paid.2006.12.012.

Siedlecki KL, Salthouse TA, Oishi S, Jeswani S. 2014. The relationship between social support and subjective wellbeing across age. Social Indicators Research 117:561-576 DOI 10.1007/s11205-013-0361-4.

Slebarska K, Moser K, Gunnesch-Luca G. 2009. Unemployment, social support, individual resources and job search behavior. Journal of Employment Counseling 46:159-170 DOI 10.1002/j.2161-1920.2009.tb00079.x.

Stankunas M, Kalediene R, Starkuviene S, Kapustinskiene V. 2006. Duration of unemployment and depression: A cross-sectional survey in Lithuania. BMC Public 
Health 6:174 DOI 10.1186/1471-2458-6-174.

Wanberg CR. 2012. The individual experience of unemployment. Annual Review of Psychology 63:369-396 DOI 10.1146/annurev-psych-120710-100500.

Wanberg CR, Kammeyer-Mueller JD, Shi K. 2001. Job loss and the experience of unemployment: International research and perspectives. In: Anderson N, Ones DS, Sinangil HK, Viswesvaran C, eds. International handbook of work and organizational psychology. London, UK: Sage, 253-269.

Wanberg CR, Zhu J, Kanfer R, Zhang Z. 2012. After the pink slip: Applying dynamic motivation frameworks to the job search experience. Academy of Management Journal 55:261-284 DOI 10.5465/amj.2010.0157.

Wills TA. 1991. Social support and interpersonal relationships. In: Clark MS, ed. Review of personality and social psychology. Thousand Oaks, CA.: Sage, 265-289.

Wong CS, Law KS. 2002. The effects of leader and follower emotional intelligence on performance and attitude: An exploratory study. The Leadership Quarterly 13:243-274 DOI 10.1016/S1048-9843(02)00099-1.

Zimet GD, Dahlem NW, Zimet SG, Farley GK. 1988. The multidimensional scale of perceived social support. Journal of Personality Assessment 52:30-41 DOI 10.1207/s15327752jpa5201_2ç.

Zeidner M, Matthews G, Roberts, RD. 2012. The emotional intelligence, health, and wellbeing nexus: What have we learned and what have we missed? Applied Psychology: Health and Well-Being 4:11-30 DOI 10.1111/j.1758-0854.2011 